\title{
Synthesis and Properties of New Molecule-Based Magnets Containing Mn(II), Cu(II) and Nitronyl Nitroxide Radical Cation
}

\author{
Maria G. F. Vaz ${ }^{a}$, Marcelo Knobel ${ }^{b}$, Nivaldo L. Speziali ${ }^{c}$, Alexandre M. Moreira, \\ Antônio F. C. Alcântara ${ }^{d}$ and Humberto O. Stumpf ${ }^{* e}$ \\ ${ }^{a}$ Centro de Desenvolvimento da Tecnologia Nuclear, CP 941, 30.123-970, Belo Horizonte - MG, Brazil \\ ${ }^{b}$ Instituto de Física Gleb Wataghin, Universidade Estadual de Campinas, CP 6165, 13.083-970, Campinas - SP, Brazil \\ ${ }^{c}$ Departamento de Física, ICEx, Universidade Federal de Minas Gerais, 31.270-901, Belo Horizonte - MG, Brazil \\ ${ }^{d}$ Departamento de Química, ICE, Fundação Universidade do Amazonas, 69.078-000, Manaus - AM, Brazil \\ ${ }^{e}$ Departamento de Química, ICEx, Universidade Federal de Minas Gerais, 31.270-901, Belo Horizonte - MG, Brazil
}

\begin{abstract}
Neste trabalho, descrevemos a obtenção de dois novos compostos de cobre(II), ou precursores, ( $\mathrm{Pr}-\mathrm{Rad})_{2}\left[\mathrm{Cu}(\right.$ opba) $] . \mathrm{H}_{2} \mathrm{O}(\mathbf{1})$ e $(\mathrm{Bu}-\mathrm{Rad})_{2}[\mathrm{Cu}(\mathrm{opba})] \cdot 2 \mathrm{H}_{2} \mathrm{O}(\mathbf{2})$, onde opba é o ligante ortofenilenobis(oxamato) e $\mathrm{R}-\mathrm{Rad}^{+}$são radicais cátions do tipo nitronil nitróxido. A partir destes compostos 1 e 2, foram sintetizados os dois novos magnetos moleculares [Pr-Rad $]_{2}\left[\mathrm{Mn}_{2}\{\mathrm{Cu}(\mathrm{opba})\}_{3}\right] .3,3$ DMSO. $5 \mathrm{H}_{2} \mathrm{O}(3)$ e $[\mathrm{Bu}-\mathrm{Rad}]_{2}\left[\mathrm{Mn}_{2}\{\mathrm{Cu}(\mathrm{opba})\}_{3}\right] .3 \mathrm{DMSO} .6 \mathrm{H}_{2} \mathrm{O}(4)$, respectivamente. As propriedades magnéticas dos precursores 1 e $\mathbf{2}$ mostram a presença de interações ferromagnéticas entre os radicais cátions e o cobre (II), na faixa de temperatura entre 20 e $300 \mathrm{~K}$. Os magnetos moleculares 3 e 4 exibem magnetização espontânea com temperatura crítica, T, de $23 \mathrm{~K}$ e $24 \mathrm{~K}$, respectivamente.
\end{abstract}

In this work, we describe the synthesis of two new copper(II) compounds, (Pr-Rad) $\left[\mathrm{Cu}(\right.$ opba) $] \cdot \mathrm{H}_{2} \mathrm{O}(\mathbf{1})$ and $(\mathrm{Bu}-\mathrm{Rad})_{2}\left[\mathrm{Cu}(\right.$ opba) $] \cdot 2 \mathrm{H}_{2} \mathrm{O}(\mathbf{2})$ where opba stands for orthophenylenebis(oxamato) and $\mathrm{R}-\mathrm{Rad}^{+}$are nitronyl nitroxide radical cations. From $\mathbf{1}$ and $\mathbf{2}$, two new molecule-based magnets [Pr- $\mathrm{Rad}]_{2}\left[\mathrm{Mn}_{2}\{\mathrm{Cu}(\text { opba })\}_{3}\right] .3 .3 \mathrm{DMSO} \cdot 5 \mathrm{H}_{2} \mathrm{O}(3)$ and $[\mathrm{Bu}-\mathrm{Rad}]_{2}$ $\left[\mathrm{Mn}_{2}\{\mathrm{Cu}(\mathrm{opba})\}_{3}\right] .3 \mathrm{DMSO} .6 \mathrm{H}_{2} \mathrm{O}(4)$ were obtained, respectively. The magnetic properties of precursors 1 and $\mathbf{2}$ show the presence of ferromagnetic interaction between the radical cations with copper(II), in the temperature range of $20-300 \mathrm{~K}$. The magnets 3 and $\mathbf{4}$ exhibit spontaneous magnetization at critical temperatures, $\mathrm{T}_{\mathrm{c}}$, of $23 \mathrm{~K}$ and $24 \mathrm{~K}$, respectively.

Keywords: supramolecular chemistry, molecule-based magnets, molecular materials, catenanes, ferrimagnetism

\section{Introduction}

As evidenced by the remarkable increase in publications on the topic, the field of molecule-based magnetism is flourishing. However, the critical temperature of the molecule-based magnets remains low and up to now there have not been compounds of this type used for any technological application. Four molecule-based magnets have been reported to remain magnetically ordered near room temperature. ${ }^{1-3}$ One of them decomposes at $350 \mathrm{~K}$, and the other three demagnetize near $315 \mathrm{~K}$. The crystal

*e-mail: stumpf@dedalus.lcc.ufmg.br. structures of these compounds have not all been determined.

One of the outstanding features of molecule-based materials is that the magnetic properties may be transformed by quite small and subtle modifications in the molecular chemistry. Variations in the organic molecules may lead to modifications in the magnetism of the material. Sometimes the molecular fragments only serve as spacers and are not involved directly in the interaction between neighboring atoms. ${ }^{4}$ In other cases, the organic part, although not possessing magnetic moment or not being responsible for the transmission of the interaction is essential to the exchange process. ${ }^{5}$ In the last few years, numerous magnetic molecular units carrying spin and able to establish 
chemical connections with other magnetic units have been developed and investigated. ${ }^{6}$ Several magnetic studies have been performed on these polynuclear systems and theoretical models have been created to correlate the experimental results (susceptibility, magnetization) with the respective Hamiltonian. ${ }^{7}$ Comparing the theoretical models and the experimental data, it is possible to determine the exchange and/or anisotropy parameters of the system. The results confirm or contradict the type of interaction initially foreseen or desired (antiferromagnetic or ferromagnetic). From these studies, it is conceivable to elaborate new synthetic strategies to tailor materials with specific properties.

The first examples of molecular materials possessing the properties of magnets appeared in 1986. Miller ${ }^{8}$ and co-workers, synthesized an organometallic compound with the formula $\left[\mathrm{Fe}\left(\mathrm{Me}_{5} \mathrm{Cp}\right)_{2}\right][\mathrm{TCNE}]\left(\mathrm{Me}_{5} \mathrm{Cp}=\right.$ pentamethylcyclopentadienyl; $\mathrm{TCNE}=$ tetracyanoethylene) that presented a magnetic critical temperature $\mathrm{T}_{\mathrm{c}}$ equal to 4.8 K. Simultaneously, Kahn ${ }^{9}$ and co-workers, described the synthesis of the coordination compound $\left[\mathrm{MnCu}(\mathrm{pbaOH})\left(\mathrm{H}_{2} \mathrm{O}\right)_{3}\right],(\mathrm{pbaOH}=2$-hydroxy-1,3-propylenebis(oxamato)) with $\mathrm{T}_{\mathrm{c}}=4.6 \mathrm{~K}$.

In the beginning of the nineties, we initiated a research in the direction to increase the dimensionality of the compounds using a more 'organic' building block: $[\mathrm{Cu}(\text { opba })]^{2-}$ where opba stands for ortho-phenylenebis(oxamato) (see Figure 1a). We succeeded in designing two-dimensional magnets of formula [cat $]_{2}\left[\mathrm{M}_{2}\right.$ $\left.\{\mathrm{Cu}(\text { opba })\}_{3}\right] . \mathrm{S}$, where $\mathrm{cat}^{+}$is a monovalent cation and $\mathrm{S}$ stands for solvent molecules. The first reported example ${ }^{10}$ of this series was the soft molecule-based magnet $\left[\mathrm{Bu}_{4} \mathrm{~N}\right]_{2}\left[\mathrm{Mn}_{2}\{\mathrm{Cu}(\text { opba })\}_{3}\right] .6 \mathrm{DMSO} \cdot \mathrm{H}_{2} \mathrm{O}$, with $\mathrm{T}_{\mathrm{c}}=15 \mathrm{~K}$. When $\mathrm{M}=\mathrm{Co}(\mathrm{II})$, a hard magnet ${ }^{11}$ is obtained $\left(\mathrm{H}_{\mathrm{c}}=3000\right.$ Oe), namely the $\left[\mathrm{Bu}_{4} \mathrm{~N}\right]_{2}\left[\mathrm{Co}_{2}\{\mathrm{Cu}(\text { opba })\}_{3}\right] \cdot 3 \mathrm{DMSO} \cdot 3 \mathrm{H}_{2} \mathrm{O}$ with $\mathrm{T}_{\mathrm{c}}$ of the order of $32 \mathrm{~K}$.

In 1993, we obtained the compound [Me-Rad] ${ }_{2}$ $\left[\mathrm{Mn}_{2}\{\mathrm{Cu}(\text { opba })\}_{3}\right](\mathrm{DMSO})_{2} \cdot 2 \mathrm{H}_{2} \mathrm{O},{ }^{12}$ where $\mathrm{Me}-\mathrm{Rad}^{+}$is a nitronyl nitroxide radical cation (see Figure $1 \mathrm{~b}$ ). This compound, a magnet with $\mathrm{T}_{c}$ of $22 \mathrm{~K}$, presents a rare interlocked structure. Moreover, by the time of the

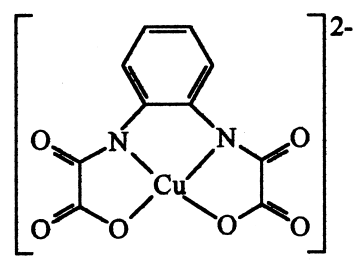

a

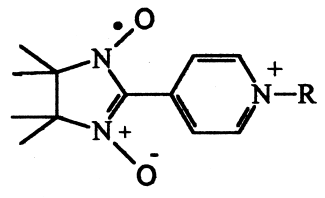

b
Figure 1. a) $[\mathrm{Cu}(\mathrm{opba})]^{2-}$ building block; b) nitronyl nitroxide radical cations, R-Rad ${ }^{+}$ description of this compound, no molecular magnets were known with a resolved structure and $\mathrm{T}_{\mathrm{c}}$ above of $15 \mathrm{~K}$.

A large number of reports have appeared in the literature on this $[\mathrm{cat}]_{2}\left[\mathrm{M}_{2}\{\mathrm{Cu}(\mathrm{opba})\}_{3}\right]$.S system involving theoretical ${ }^{13,14}$ and different experimental studies, ${ }^{15-17}$ aiming the development of models to explain the observed magnetic behaviors. Also, numerous reports explored the potentialities of these bimetallic compounds ${ }^{18,19}$ through chemical variations. Although several groups have been working on this system, only recently the reproduction of the interlocked structure of the compound [Me-Rad $]_{2}\left[\mathrm{Mn}_{2}\right.$ $\left.\{\mathrm{Cu}(\text { opba })\}_{3}\right](\mathrm{DMSO})_{2} \cdot 2 \mathrm{H}_{2} \mathrm{O}$ was achieved. ${ }^{20,21}$

In this work we describe the synthesis of two new precursors $(\mathrm{Pr}-\mathrm{Rad})_{2}[\mathrm{Cu}(\mathrm{opba})] \cdot \mathrm{H}_{2} \mathrm{O}(\mathbf{1})$ and $(\mathrm{Bu}-\mathrm{Rad})_{2}$ $[\mathrm{Cu}(\mathrm{opba})] \cdot 2 \mathrm{H}_{2} \mathrm{O}(\mathbf{2})$, and two new molecule-based magnets, $[\mathrm{Pr}-\mathrm{Rad}]_{2}\left[\mathrm{Mn}_{2}\{\mathrm{Cu}(\text { opba })\}_{3}\right]$.3.3DMSO.5 $\mathrm{H}_{2} \mathrm{O}(\mathbf{3})$ and $[\mathrm{Bu}-\mathrm{Rad}]_{2}\left[\mathrm{Mn}_{2}\{\mathrm{Cu}(\mathrm{opba})\}_{3}\right] .3 \mathrm{DMSO} \cdot 6 \mathrm{H}_{2} \mathrm{O}(4)$. With the present study we intended to verify the influence of changes in the radical cation in the interlocked structure, as well as the effect of these changes on the critical temperature. The results obtained through X-ray structural analysis, magnetic properties and elemental analysis and the critical temperature of the compounds indicate the interlocked structure to be the most likely for these new molecule-based magnets.

\section{Experimental}

Syntheses: The radical 2-(pyridine-4-yl)-4,4,5,5tetramethylimidazoline-1-oxyl-3-oxide, abbreviated as $\mathrm{Rad},{ }^{22}$ the ligand opba, and the tetrabutylammonium salt of the copper(II) precursor $\left(\mathrm{Bu}_{4} \mathrm{~N}\right)_{2}[\mathrm{Cu}($ opba $)]$ were prepared as already described. ${ }^{10}$

$\operatorname{Pr}-\operatorname{Rad}^{+} I$ : A mixture of $1.00 \mathrm{~g}(4.3 \mathrm{mmol})$ of $\mathrm{Rad}$ in $4.5 \mathrm{~mL}$ ( $7.85 \mathrm{~g}, 46 \mathrm{mmol}$ ) of 1-iodopropane and $1.0 \mathrm{~mL}$ of THF was stirred for $48 \mathrm{~h}$, at $45^{\circ} \mathrm{C}$. The green precipitate was collected by filtration, washed with THF and dried under vacuum. Yield: $1.42 \mathrm{~g}(82 \%)$. Anal. Calc. for $\mathrm{C}_{15} \mathrm{H}_{23} \mathrm{~N}_{3} \mathrm{O}_{2} \mathrm{I}: \mathrm{C}, 44.56 ; \mathrm{H}, 5.75 ; \mathrm{N}, 10.40$. Found: C, 44.35; $\mathrm{H}, 5.77 ; \mathrm{N}, 10.26 \%$.

$B u-\operatorname{Rad}^{+} I:$ A mixture of $1.0 \mathrm{~g}(4.3 \mathrm{mmol})$ of $\mathrm{Rad}$ in $5.0 \mathrm{~mL}(8.1 \mathrm{~g}, 44 \mathrm{mmol})$ of 1-iodobutane and $1.0 \mathrm{~mL}$ of THF was kept under stirring for $72 \mathrm{~h}$, at $45^{\circ} \mathrm{C}$. The yellowgreen precipitate was isolated by filtration, washed with THF and dried under vacuum. Yield: $1.12 \mathrm{~g}(62 \%)$. Anal. Calc. for $\mathrm{C}_{16} \mathrm{H}_{25} \mathrm{~N}_{3} \mathrm{O}_{2} \mathrm{I}: \mathrm{C}, 45.93 ; \mathrm{H}, 6.04 ; \mathrm{N}, 10.05$. Found: C, $45.85 ; \mathrm{H}, 5.68 ; \mathrm{N}, 9.48 \%$.

$(\mathrm{Pr}-\mathrm{Rad})_{2}[\mathrm{Cu}(\mathrm{opba})] \cdot \mathrm{H}_{2} \mathrm{O}(\mathbf{1}):$ A solution of $0.69 \mathrm{~g}$ $(0.86 \mathrm{mmol})$ of $\left(\mathrm{Bu}_{4} \mathrm{~N}\right)_{2}[\mathrm{Cu}(\mathrm{opba})]$ in $15 \mathrm{~mL}$ of dichlorometane was added to a solution of $0.7 \mathrm{~g}(1.73 \mathrm{mmol})$ of Pr-Rad ${ }^{+} \mathrm{I}^{-}$in $7.0 \mathrm{~mL}$ of chloroform. The mixture was heated at $40{ }^{\circ} \mathrm{C}$ and stirred for $90 \mathrm{~min}$. The resulting brown 
polycrystalline precipitate was collected by filtration, washed with a $2: 1 \mathrm{CH}_{2} \mathrm{Cl}_{2} / \mathrm{CHCl}_{3}$ mixture, and dried in a dessicator under vacuum. Yield: $0.46 \mathrm{~g}(60 \%)$. Anal. Calc. for $\mathrm{C}_{40} \mathrm{H}_{52} \mathrm{~N}_{8} \mathrm{O}_{11} \mathrm{Cu}: \mathrm{C}, 54.32 ; \mathrm{H}, 5.88 ; \mathrm{N}, 12.67 ; \mathrm{Cu}, 7.18$. Found: C, 54.58; H, 5.92; N, 12.12; Cu, 6.94\%.

$(\mathrm{Bu}-\mathrm{Rad})_{2}[\mathrm{Cu}(\mathrm{opba})] \cdot 2 \mathrm{H}_{2} \mathrm{O}(2)$ : A solution of $0.53 \mathrm{~g}$ $(0.67 \mathrm{mmol})$ of $\left(\mathrm{Bu}_{4} \mathrm{~N}\right)_{2}[\mathrm{Cu}(\mathrm{opba})]$ in $2.0 \mathrm{~mL}$ of dichlorometane was added to a solution of $0.56 \mathrm{~g}(1.35 \mathrm{mmol})$ of $\mathrm{Bu}-\mathrm{Rad}^{+} \mathrm{I}^{-}$in $4.0 \mathrm{~mL}$ of chloroform under stirring at room temperature. The mixture was stirred for $30 \mathrm{~min}$. The resulting brown polycrystalline precipitate was collected by filtration, washed with a $1: 2 \mathrm{CH}_{2} \mathrm{Cl}_{2} / \mathrm{CHCl}_{3}$ mixture, and dried in a dessicator under vacuum. Yield: $0.44 \mathrm{~g}(71 \%)$. Anal. Calc. for $\mathrm{C}_{42} \mathrm{H}_{58} \mathrm{~N}_{8} \mathrm{O}_{12} \mathrm{Cu}: \mathrm{C}, 54.21 ; \mathrm{H}, 6.23 ; \mathrm{N}, 12.04$; $\mathrm{Cu}, 6.83$. Found: $\mathrm{C}, 54.20 ; \mathrm{H}, 5.95 ; \mathrm{N}, 11.96 ; \mathrm{Cu}, 6.43 \%$.

[Pr-Rad $]_{2}\left[\mathrm{Mn}_{2}\{\mathrm{Cu}(\mathrm{opba})\}_{3}\right] .3 .3 \mathrm{DMSO} .5 \mathrm{H}_{2} \mathrm{O}(\mathbf{3}): \mathrm{A}$ solution of $0.010 \mathrm{~g}(0.056 \mathrm{mmol})$ of $\mathrm{MnCl}_{2} .3 \mathrm{H}_{2} \mathrm{O}$ in $1.4 \mathrm{~mL}$ of DMSO was added to a solution of $0.21 \mathrm{~g}(0.23 \mathrm{mmol})$ of 1 in $6.4 \mathrm{~mL}$ of DMSO. The mixture was stirred at room temperature for $10 \mathrm{~min}$. The color slowly turned green. The solution was then distributed into several shallow beakers that were then sealed and allowed to stand. The first crystals appeared within a few hours. They were collected after 5 days, washed with DMSO, and dried in a dessicator. Yield: $0.043 \mathrm{~g}(79 \%)$. Anal. Calc. for $\mathrm{C}_{67} \mathrm{H}_{88} \mathrm{~N}_{12} \mathrm{O}_{30} \mathrm{~S}_{3.3} \mathrm{Cu}_{3} \mathrm{Mn}_{2}: \mathrm{C}$, $41.07 ; \mathrm{H}, 4.51 ; \mathrm{N}, 8.63 ; \mathrm{S}, 5.44 ; \mathrm{Cu}, 9.79 ; \mathrm{Mn}, 5.64$. Found: C, 40.84; H, 4.28; N, 8.60; S, 5.40; Cu, 9.90; Mn, 5.38\%.

$[\mathrm{Bu}-\mathrm{Rad}]_{2}\left[\mathrm{Mn}_{2}\{\mathrm{Cu}(\mathrm{opba})\}_{3}\right] .3 \mathrm{DMSO} \cdot 6 \mathrm{H}_{2} \mathrm{O}(\mathbf{4}): \mathrm{A}$ solution of $0.0068 \mathrm{~g}(0.038 \mathrm{mmol})$ of $\mathrm{MnCl}_{2} \cdot 3 \mathrm{H}_{2} \mathrm{O}$ in $1.3 \mathrm{~mL}$ of DMSO was added to a solution of $0.25 \mathrm{~g}(0.27$ $\mathrm{mmol}$ ) of $\mathbf{2}$ in $7.0 \mathrm{~mL}$ of DMSO. The mixture was stirred at room temperature for $10 \mathrm{~min}$. The color slowly turned to green. The crystallization procedure was the same used for 3. The crystals were collected after 3 days, washed with DMSO, and dried in a dessicator. Yield: $0.034 \mathrm{~g}(91 \%)$. Anal. Calc. for $\mathrm{C}_{68} \mathrm{H}_{92} \mathrm{~N}_{12} \mathrm{O}_{30} \mathrm{~S}_{3} \mathrm{Cu}_{3} \mathrm{Mn}_{2}: \mathrm{C}, 41.45 ; \mathrm{H}, 4.67$; N, 8.53; S, 4.89; Cu, 9.67; Mn, 5.58. Found: C, 41.41; H, 4.33; N, 8.66; S, 4.61; Cu, 9.90; Mn, 5.51\%.

Physical Techniques: X-ray powder diffraction studies were performed in a Rigaku- Geigerflex equipment. Data were collected in the Bragg-Bretano mode with $2 \mathrm{q}$ varying from 4.0 to 40 and using a $0.020833^{\circ}$ step; monochromatic $\mathrm{CuK} \alpha$ radiation was used. Elemental analyses $(\mathrm{C}, \mathrm{H}, \mathrm{N}$, $\mathrm{Mn}, \mathrm{Cu}$ ) were performed on a Perkin-Elmer 2400 apparatus. The magnetic properties were studied in the Quantum Design MPMS XL7 SQUID magnetometer, working in the dc mode between 2 and $300 \mathrm{~K}$. The raw susceptibility data were corrected for the core diamagnetism estimated as: $-397 \times 10^{-6}$ and $-433 \times 10^{-6} \mathrm{emu} \mathrm{mol}^{-1}$ for the precursors 1 and 2 , respectively and $-790 \times 10^{-6}$ and $-766 \times 10^{-6} \mathrm{emu} \mathrm{mol}^{-1}$ for the magnets $\mathbf{3}$ and $\mathbf{4}$, respectively.

\section{Results and Discussion}

The synthesis of the magnets is very sensitive to the purity of the precursors and some other parameters. To

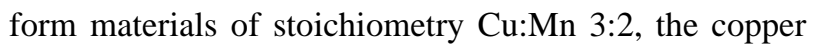
building block must be present in excess. If the $\mathrm{Cu}: \mathrm{Mn}$ ratio in the solution is low, formation of $\mathrm{MnCu}$ (opba) chains $^{23}$ occurs instead. The effect of reagents' concentration upon the reaction and on the formation of crystals is crucial. If the solution is over diluted no product is obtained, as $\mathrm{Mn}$ (II) is slightly sensitive and decomposes before or during the crystallization, producing an insoluble brown impurity. The use of water as a solvent favors formation of chains and the use of chloride is preferable to other salts.

A variety of experiments were performed to find the best crystallization conditions. Beyond variations of concentration and $\mathrm{Cu}: \mathrm{Mn}$ ratio, other parameters were considered such as the temperature, the type of crystallization flask (glass or polystyrene) and mixture of solvents. Regarding the stability of the magnets, it should be pointed out that, after removal from the mother liquor, they could be stored in a freezer for several months.

\section{Precursors}

The magnetic susceptibility data for $\mathbf{1}$ and $\mathbf{2}$ are shown in Figure 2 in the form of the $\chi_{\mathrm{M}} \mathrm{T}$ versus $\mathrm{T}$ plot, $\chi_{\mathrm{M}}$ being the molar magnetic susceptibility and $\mathrm{T}$ the temperature.

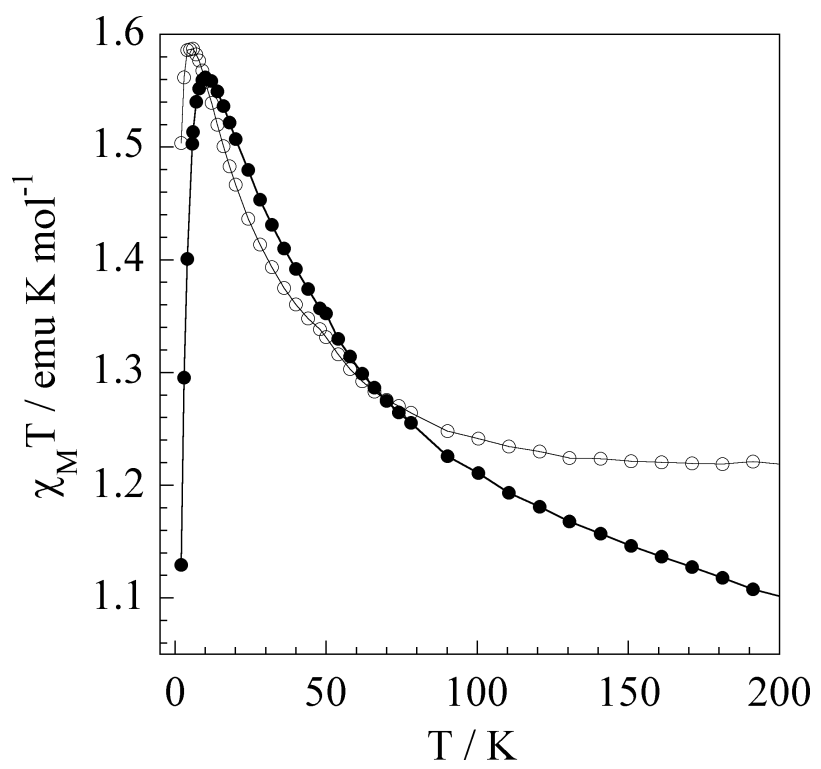

Figure 2. $\chi_{\mathrm{M}} \mathrm{T}$ versus $\mathrm{T}$ plot, at $1000 \mathrm{Oe}$, for $(\mathrm{Pr}-\mathrm{Rad})_{2}[\mathrm{Cu}(\mathrm{opba})] \cdot \mathrm{H}_{2} \mathrm{O}$ (•) and $(\mathrm{Bu}-\mathrm{Rad})_{2}[\mathrm{Cu}(\mathrm{opba})] \cdot 2 \mathrm{H}_{2} \mathrm{O}(\mathrm{O})$. The full lines are guides for the eye 
At room temperature $\chi_{\mathrm{M}} \mathrm{T}$ is equal to $1.05 \mathrm{emu} \mathrm{K} \mathrm{mol}^{-1}$ for $\mathbf{1}$ and $1.21 \mathrm{emu} \mathrm{K} \mathrm{mol}^{-1}$ for $\mathbf{2}$. These values are close to the theoretical value expected for 3 isolated spins $S=1 / 2$ (two spins referring to the radicals and one to the copper) that can be calculated by the Curie law:

$$
\chi_{\mathrm{M}}=\mathrm{C} / \mathrm{T}=\mathrm{N} \beta^{2} g^{2} \mathrm{~S}(\mathrm{~S}+1) / 3 \mathrm{k} \mathrm{T}
$$

Substituting the Bohr magneton $(\beta)$ and Boltzmann constant (k) values into equation (1):

$$
\chi_{\mathrm{M}}^{\mathrm{T}}=1 / 8\left[g^{2} \mathrm{~S}(\mathrm{~S}+1)\right]
$$

and substituting the $S$ value in equation (2) and considering $g=2$ :

$$
\chi_{\mathrm{M}} \mathrm{T}=1.125 \mathrm{emu} \mathrm{K} \mathrm{mol}{ }^{-1}
$$

As T is lowered, $\chi_{\mathrm{M}} \mathrm{T}$ first increases, reaches a maximum at $10.6 \mathrm{~K}$ and $6.1 \mathrm{~K}$ with $\chi_{\mathrm{M}} \mathrm{T}=1.56 \mathrm{emu} \mathrm{\textrm {Kol } ^ { - 1 }}$ and 1.59 emu $\mathrm{K} \mathrm{mol}^{-1}$ for $\mathbf{1}$ and $\mathbf{2}$, respectively, and finally decreases rapidly. The profile of this curve indicates that in the two compounds some ferromagnetic interactions are operative. The decrease of $\chi_{\mathrm{M}} \mathrm{T}$ in the low-temperature region may be attributed to intermolecular interactions.

The magnetic properties for the analogous precursor (Et-Rad) ${ }_{2}[\mathrm{Cu}($ opba $)] \cdot \mathrm{CH}_{3} \mathrm{CN} \cdot \mathrm{H}_{2} \mathrm{O}$ has already been described. ${ }^{20}$ Its $\chi_{\mathrm{M}}$ T versus T curve shows the same outline as those of $\mathbf{1}$ and $\mathbf{2}$ and corresponds to a dimer ferromagnetically coupled and a spin $S=1 / 2$ isolated. Gatteschi and co-workers have already shown that the orthogonality of a copper $d_{x^{2}-y^{2}}$-type and a nitronyl nitroxide radical $p_{\pi^{-}}$ type magnetic orbitals affords ferromagnetic coupling. ${ }^{24}$ This orthogonality can be obtained, for example, if the radical occupies an apical position of the $\mathrm{Cu}$ (II) ion, as in (Et-Rad) ${ }_{2}[\mathrm{Cu}(\mathrm{opba})] \cdot \mathrm{CH}_{3} \mathrm{CN} \cdot \mathrm{H}_{2} \mathrm{O}$. The magnetic properties of this compound are very similar to those of the precursors $\mathbf{1}$ and $\mathbf{2}$, indicating that they have the same molecular structure. The structure of (Et-Rad) $)_{2}[\mathrm{Cu}(\mathrm{opba})] \cdot \mathrm{CH}_{3} \mathrm{CN} \cdot \mathrm{H}_{2} \mathrm{O}$ has been solved by a single crystal X-ray diffraction analysis and, as shown in Figure 3, consists of one $[\mathrm{Cu}(\mathrm{opba})]^{2-}$, two radical cations and molecules of $\mathrm{CH}_{3} \mathrm{CN}$ and $\mathrm{H}_{2} \mathrm{O}$ not coordinated. One of the radical cations is weakly linked to the copper while the other is relatively isolated.

X-ray powder diffraction were performed for $\mathbf{1}$ and $\mathbf{2}$ and the Rietveld method has been employed in structural analysis. For the sake of comparison, diffraction data were also obtained for (Et-Rad) ${ }_{2}[\mathrm{Cu}(\mathrm{opba})] \cdot \mathrm{CH}_{3} \mathrm{CN} \cdot \mathrm{H}_{2} \mathrm{O}$ and its crystal structure ${ }^{20}$ was used as a reference. The results obtained for the structure refinements for the three

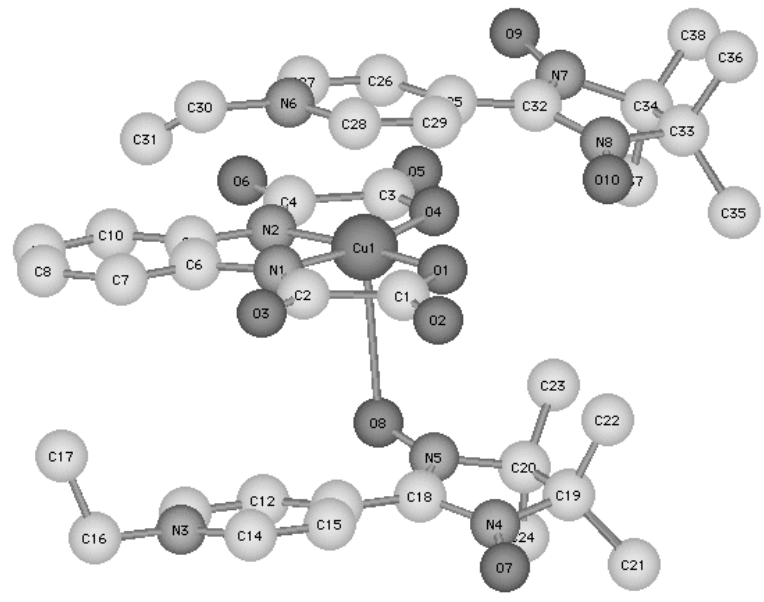

Figure 3. Molecular structure of (Et-Rad) ${ }_{2}[\mathrm{Cu}($ opba $)] \cdot \mathrm{CH}_{3} \mathrm{CN} \cdot \mathrm{H}_{2} \mathrm{O}^{30}$. For the sake of simplicity solvent molecules are not represented (open circles $=$ carbon, cross-hatched circles = oxigen, hatched circles $=$ nitrogen $)$

compounds are not of best quality. Nevertheless, as in the case of the magnetic results, the similarity in the obtained parameters indicates they positively have a similar structure.

\section{Magnets}

X-ray powder diffraction study of the magnets was performed as described previously. The results strongly suggest that $\mathbf{3}$ and $\mathbf{4}$ have similar structures to those of the magnets $[\text { Et-Rad }]_{2}\left[\mathrm{M}_{2}{ }_{2}\{\mathrm{Cu}(\mathrm{opba})\}_{3}\right](\mathrm{DMSO})_{\mathrm{x}} \cdot 0.25 \mathrm{H}_{2} \mathrm{O}$, with $\mathrm{M}^{\mathrm{II}}=\mathrm{Mn}$ (II) or $\mathrm{Co}(\mathrm{II})$, for which the structures have been determined; ${ }^{20}$ the $\mathrm{Mn}(\mathrm{II})$ compound was used as a reference (see Figure 4).

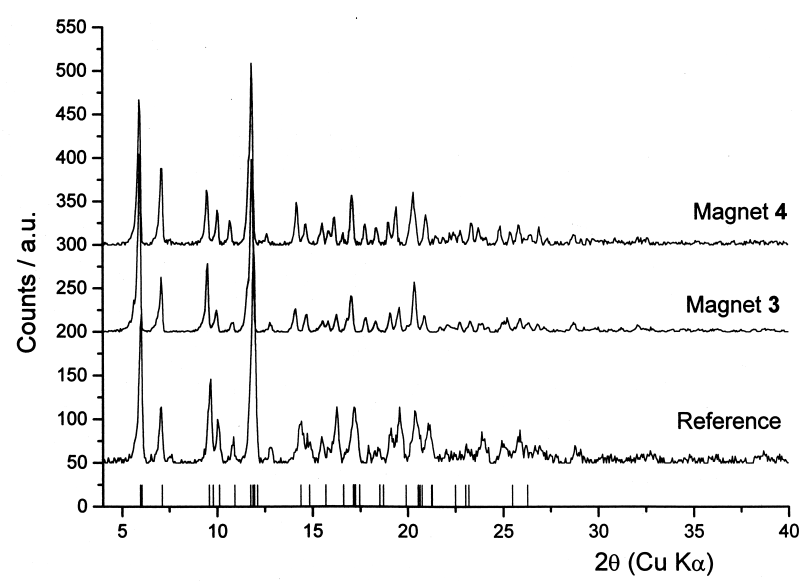

Figure 4. X-ray diffraction results for the magnets 3 and 4 and for the reference compound [Et-Rad $]_{2}\left[\mathrm{Mn}_{2}\{\mathrm{Cu}(\text { opba })\}_{3}\right](\mathrm{DMSO})_{0.5}$. $0.25 \mathrm{H}_{2} \mathrm{O} ;{ }^{20}$ the Bragg positions for the most important reflections calculated for the reference compound are indicated with bars on the bottom of the Figure 
The general architecture of the reference compound consists of two equivalent two-dimensional networks, each network being formed by parallel honeycomb layers. A layer is made up of edge-sharing hexagons with $\mathrm{Mn}(\mathrm{II})$ ions at each corner and $\mathrm{Cu}(\mathrm{II})$ ions at the middle of each edge. Two nearest neighboring metal ions are bridged by an oxamato group. The network layers stack above each other in a graphite-like fashion. The networks interpenetrate with a full interlocking of the $\mathrm{Mn}_{6} \mathrm{Cu}_{6}$ hexagons, as shown in Figure 5. The topology may be described as a threedimensional wire netting. The hexagons are connected further through radical cations that interact with two copper atoms, thus bridging the two perpendicular networks.

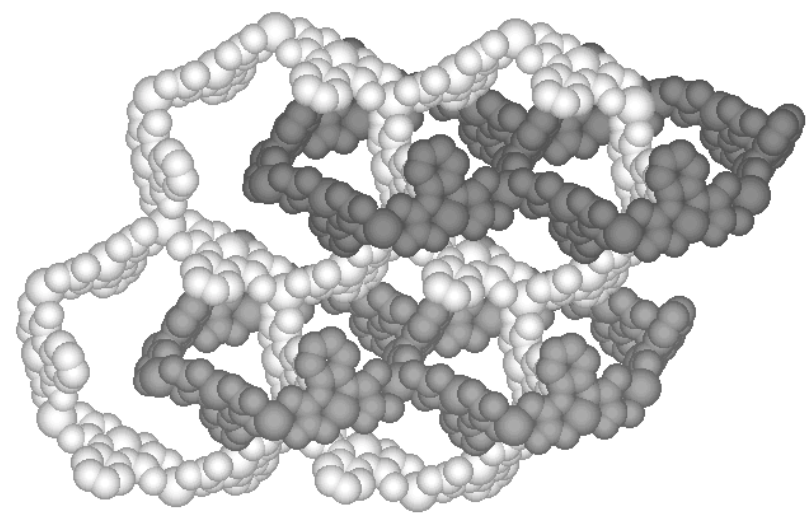

Figure 5. Schematic representation of the interpenetration of the honeycomb layers of the $\mathrm{M}_{6} \mathrm{Cu}_{6}$ hexagons. The organic radicals and the solvent molecules have been omitted for the sake of clarity

The $\chi_{\mathrm{M}} \mathrm{T}$ versus $\mathrm{T}$ plot for $\mathbf{4}$ is shown in Figure 6. This curve is characteristic of ferrimagnetic compounds ${ }^{25}$ of formula $[\mathrm{cat}]_{2}\left[\mathrm{Mn}_{2}\{\mathrm{Cu}(\mathrm{opba})\}_{3}\right] . \mathrm{S}$ ( $\mathrm{S}=$ solvent molecule).

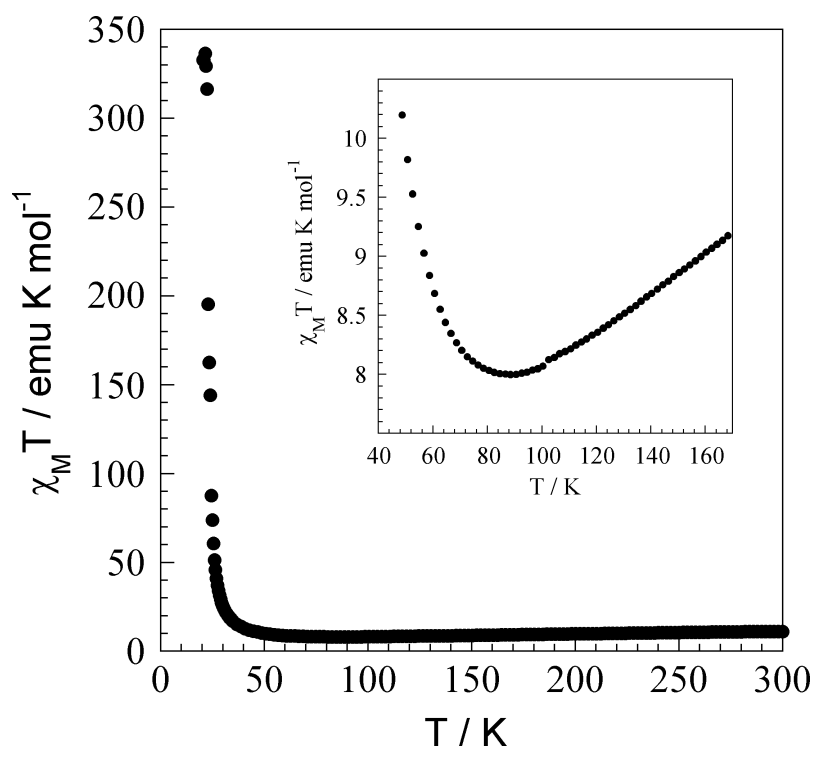

Figure 6. $\chi_{\mathrm{M}} \mathrm{T}$ versus $\mathrm{T}$ plot, at $1000 \mathrm{Oe}$, for $[\mathrm{Bu}-\mathrm{Rad}]_{2}\left[\mathrm{Mn}_{2}\right.$ $\left.\{\mathrm{Cu}(\text { opba })\}_{3}\right] .3 \mathrm{DMSO} .6 \mathrm{H}_{2} \mathrm{O}$
At room temperature, $\chi_{\mathrm{M}} \mathrm{T}$ is equal to $8.8 \mathrm{emu} \mathrm{K} \mathrm{mol}^{-1}$, which is slightly lower than expected for two radical, two high-spin $\mathrm{Mn}(\mathrm{II})$ and three $\mathrm{Cu}(\mathrm{II})$ isolated ions (expected value: $10.6 \mathrm{emu} \mathrm{K} \mathrm{mol}^{-1}$ ). It should be reminded that the model used in the calculation of the theoretical value of $\chi_{\mathrm{M}} \mathrm{T}$ considers that, at room temperature, there is no interaction between the spins, which is an approximation. As $\mathrm{T}$ is lowered, $\chi_{\mathrm{M}} \mathrm{T}$ first decreases smoothly, reaches a minimum around $90 \mathrm{~K}$ with $\chi_{\mathrm{M}} \mathrm{T}=8.1 \mathrm{emu} \mathrm{K} \mathrm{mol}{ }^{-1}$ and then increases very abruptly. The minimum in the $\chi_{\mathrm{M}} \mathrm{T}$ versus $\mathrm{T}$ plot is characteristic of a ferrimagnetic material. ${ }^{26}$ At high temperature, $\chi_{\mathrm{M}} \mathrm{T}$ approaches the paramagnetic limit. As $\mathrm{T}$ is lowered, the decrease in $\chi_{\mathrm{M}} \mathrm{T}$ corresponds to a short-range order where the local spins $\mathrm{S}_{\mathrm{Cu}}$ and $\mathrm{S}_{\mathrm{Mn}}$ of adjacent metal ions are aligned antiparallel but have no correlation with neighboring $\mathrm{MnCu}$ units. As $\mathrm{T}$ is further lowered, below the $\chi_{\mathrm{M}} \mathrm{T}$ minimum, the randomizing thermal effects are reduced and the correlation length increases. This leads to a spontaneous magnetization below a critical temperature. There is no theoretical model to interpret quantitatively these magnetic data due to the complexity of the structure, as well as the presence of three kinds of spin carriers. However, for compounds $\left[\mathrm{Bu}_{4} \mathrm{~N}\right]_{2}\left[\mathrm{Mn}_{2}\right.$ $\left.\{\mathrm{Cu}(\mathrm{opba})\}_{3}\right] . \mathrm{S}$, there are studies ${ }^{14}$ that allowed to evaluate the coupling constant between $\mathrm{Mn}$ (II) and $\mathrm{Cu}$ (II) as $J=$ $-33.1 \mathrm{~cm}^{-1}$ (with $\mathrm{g}_{\mathrm{Mn}}=2.0$ and $\mathrm{g}_{\mathrm{Cu}}=2.2$ ). From the similarity of the magnetic behavior of $\left[\mathrm{Bu}_{4} \mathrm{~N}\right]_{2}\left[\mathrm{Mn}_{2}\{\mathrm{Cu}(\text { opba })\}_{3}\right] . \mathrm{S}$ and the magnets $\mathbf{3}$ and $\mathbf{4}$, in this temperature range, we can affirm that the interaction between $\mathrm{Mn}(\mathrm{II})$ and $\mathrm{Cu}$ (II) in these compounds is antiferromagnetic with nearly the same intensity. From the $\chi_{\mathrm{M}} \mathrm{T}$ curve it is not possible to determine the specific behavior of the radical cation spins. However, measurements on the compound ${ }^{27}$ [Et-Rad $]_{2}\left[\mathrm{Mg}_{2}\right.$ $\{\mathrm{Cu}(\text { opba })\}_{3}$ ].4.5DMSO.5.5 $\mathrm{H}_{2} \mathrm{O}$ confirmed that the radical cation interacts ferromagnetically with the $\mathrm{Cu}$ (II). It follows that the radical spins tend to align along a direction opposite to that of the $\mathrm{S}_{\mathrm{Mn}}$ spins.

The temperature dependence of the molar magnetization $\mathbf{M}$ for $\mathbf{3}$ and $\mathbf{4}$ were investigated with an applied magnetic field $\mathrm{H}$ of 10 Oe. Figure 7 shows the results for 3 .

The curve increases very rapidly starting from $24 \mathrm{~K}$ and reaching a maximum value of magnetization of 2600 emu Oe $\mathrm{mol}^{-1}$. This behavior is attributed ${ }^{28}$ to the appearance of magnetic order around $23 \mathrm{~K}$. At the critical temperature, the magnetization increases abruptly, but its value is limited (the saturation magnetization is not reached) by the effects of the demagnetizing field and domains. ${ }^{26}$ Compound $\mathbf{4}$ presents a similar behavior, with $\mathrm{a} \mathrm{T}_{\mathrm{c}}$ of $24 \mathrm{~K}$.

The field dependence of the magnetization for $\mathbf{3}$, at $5 \mathrm{~K}$, is shown in Figure 8. 


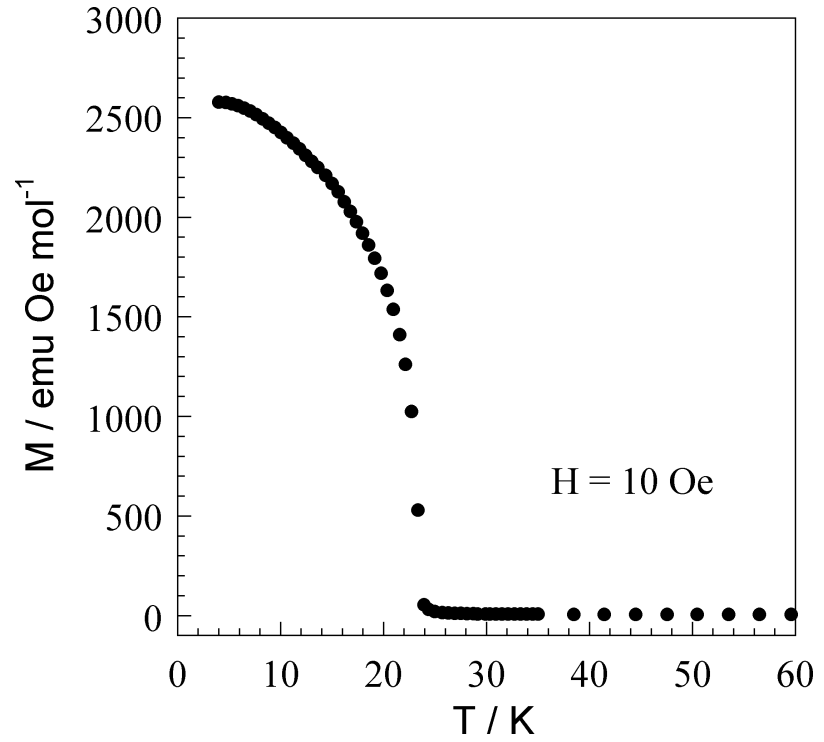

Figure 7. Magnetization versus temperature curve for $[\mathrm{Pr}-\mathrm{Rad}]_{2}\left[\mathrm{Mn}_{2}\right.$ $\left.\{\mathrm{Cu}(\mathrm{opba})\}_{3}\right] .3 .3 \mathrm{DMSO} .5 \mathrm{H}_{2} \mathrm{O}$ within a field of $10 \mathrm{Oe}$

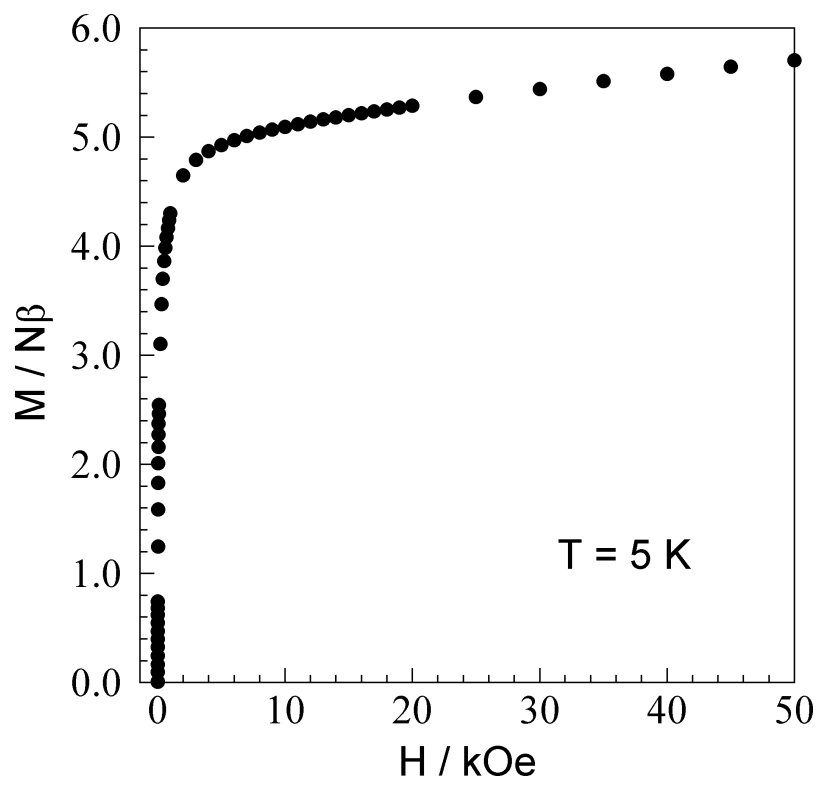

Figure 8. Magnetization versus magnetic field curve, at $5 \mathrm{~K}$, for $[\mathrm{Pr}-\mathrm{Rad}]_{2}\left[\mathrm{Mn}_{2}\{\mathrm{Cu}(\text { opba })\}_{3}\right] .3 .3 \mathrm{DMSO} .5 \mathrm{H}_{2} \mathrm{O}$

The magnetization quickly increases up to a field of $2 \mathrm{kOe}$ and afterwards the slope continuously decreases. The saturation magnetization, $M_{\text {sat }}$, was not reached, even with magnetic fields up to $50 \mathrm{kOe}$. With $\mathrm{H}=2 \mathrm{kOe}$, the magnetization is $5.0 \mathrm{~N} \beta$ and with a field of $50 \mathrm{kOe}$ the value $6.4 \mathrm{~N} \beta$ is found. For [Me- $\mathrm{Rad}]_{2}\left[\mathrm{Mn}_{2}\{\mathrm{Cu}(\mathrm{opba})\}_{3}\right]$ (DMSO) $)_{2} \cdot 2 \mathrm{H}_{2} \mathrm{O},{ }^{29}$ even with the application of a magnetic field of $200 \mathrm{kOe}, \mathrm{M}_{\mathrm{sat}}$ was not reached. We can interpret this curves considering that initially the spins of the radicals and the $\mathrm{Cu}(\mathrm{II})$ ions are coupled ferromagnetically. The magnetic field destroys this ferromagnetic alignment progressively and the spins of the radicals begin to align parallel to the spins of the Mn(II) ions. This is only possible if the interaction between the organic radicals and the $\mathrm{Cu}$ (II) ions is weak. In this way, the magnetization increases starting from a value of $5 \mathrm{~N} \beta\left(2 \times 5 \mathrm{~S}_{\mathrm{Mn}}-3 \times \mathrm{S}_{\mathrm{Cu}}-2 \times \mathrm{S}_{\mathrm{Rad}}\right)$ going in the direction of a limit value of $9 \mathrm{~N} \beta\left(2 \times 5 \mathrm{~S}_{\mathrm{Mn}^{-}}\right.$ $3 \mathrm{XS}_{\mathrm{Cu}}+2 \mathrm{xS}_{\mathrm{Rad}}$ ). On the other hand, to overcome the strong coupling between $\mathrm{Mn}$ (II) and $\mathrm{Cu}(\mathrm{II})$, magnetic fields of the order of 40 Tesla ( $400 \mathrm{kOe}$ ) would be necessary, if one supposes $J_{\mathrm{Mn}-\mathrm{Cu}}$ of about $-30 \mathrm{~cm}^{-1}$. Finally, in the field dependence of the magnetization, we observe that the hysteresis loop for $\mathbf{3}$ and $\mathbf{4}$ show a coercive field smaller than 10 Oe. These compounds are therefore soft magnets.

\section{Conclusions}

The use of the building block $[\mathrm{Cu}(\mathrm{opba})]^{2-}$ presents some features that make it very attractive: i) achievement of soluble precursors in nonpolar solvents with counterions as $\mathrm{R}_{4} \mathrm{~N}^{+}$or $\mathrm{R}-\mathrm{Rad}^{+}$; ii) flexibility to introduce groups in the phenyl ring; iii) counterion carrying other properties; iv) chelate/macrocycle stability of the copper, or other metal ion and v) ligand bis-bidentate capable of bridging a large number of metal ions. Furthermore, due to the stability of the $\mathrm{Cu}$ (II) within the block, the addition of the second metal ion is facilitated since there is no metalcompetition for the coordination sites of the ligand.

In this work, some features of these building blocks have been used to insert three different spins in molecular systems. The choice of the metals obeys a ferrimagnetic strategy which consists in placing $\mathrm{Cu}(\mathrm{II})$, with a small spin $(\mathrm{S}=1 / 2)$ and another species with the greatest possible spin for a transition metal $(S=5 / 2)$. The third spin comes from a radical cation that is introduced, as well as $\mathrm{Cu}(\mathrm{II})$, from precursors $\mathbf{1}$ and $\mathbf{2}$. Already in these compounds, one observes ferromagnetic interactions between copper and the radical cation(s) as in the precursor (Et-Rad) ${ }_{2}[\mathrm{Cu}(\mathrm{opba})]$. $\mathrm{CH}_{3} \mathrm{CN} . \mathrm{H}_{2} \mathrm{O}$ previously described.

The reactions of the precursors with a manganese salt led to new molecule-based magnets $\mathbf{3}$ and $\mathbf{4}$, which present magnetic order at 23 and $24 \mathrm{~K}$, respectively. Our findings strongly suggest that the structure of these compounds consists of two nearly perpendicular graphite-like networks similar to that obtained for other compounds of this family; thus, the synthesis methods are perfectly reproducible. On the other hand, our work showed that the increase in the chain length of the alkyl group linked to the radical does not hinder the formation of this type of system.

Beside the aesthetic appeal of the structure and 
supramolecular aspects, this system presents some peculiarities in the field of magnetism itself. Thus, the change of the manganese for $\mathrm{Co}(\mathrm{II})$ leads to very hard magnets; ${ }^{20}$ in a very near future, we will report a new compound with $\mathrm{Ni}(\mathrm{II})$ in place of $\mathrm{Mn}$ (II) which shows an unprecedented behavior with negative magnetization. ${ }^{30}$ All these features illustrate the great flexibility of these systems.

\section{Acknowledgements}

The authors would like to thank the support of Conselho Nacional de Desenvolvimento Científico e Tecnológico (CNPq), Fundação Coordenação de Aperfeiçoamento de Pessoal de Nível Superior (CAPES), Fundação de Amparo à Pesquisa do Estado de Minas Gerais (FAPEMIG), and Fundação de Amparo à Pesquisa do Estado de São Paulo (FAPESP).

\section{References}

1. Miller, J.S.; Epstein, A.J.; Science 1991, 252, 1415.

2. Ferlay, S.; Mallah, T.; Ouahe, R.; Veillet, P.; Verdaguer, M.; Nature, 1995, 378, 701.

3. Dujardin, E.; Ferlay, S.; Phan, X.; Desplanches, C.; Cartierdit-Moulin, C.; Sainctavit, P.; Baudelet, E.; Veillet, P.; Verdaguer, M.; J. Am. Chem. Soc. 1998, 120, 11347.

4. Salyer, P.A.; Haar, L.W. In Molecule-Based Magnetic Materials; Awaga, K.; Okawa, H.; Sugimoto, T.; Thompson, L.K.; Turnbull, M.M., eds.; ACS Symposium Series, 1996, 4, 127.

5. Carlin, R.L. In Magnetochemistry, Springer Verlag: New York, 1986.

6. Gordon-Wylie, S.W.; Claus, B.L.; Horwitz, C.P.; Leychkis, Y.; Worman, J.M.; Marzec, A.J.; Clark, G.R.; Rickard, C.E.F.; Conklin, B.J.; Sellers, S.; Yee, G.T.; Collins, T.J.; Chem. Eur. J. 1998, 4, 2173.

7. Alcântara, A.F.C.; Veloso, D.P.; Stumpf, H.O.; Almeida, W.B.; Tetrahedron, 1997, 53, 16911; Alcântara, A.F.C.; Dos Santos, H.F.; Almeida, W.B.; Vaz, M.G.F.; Pinheiro, L.M.M.; Stumpf, H.O.; Struct. Chem., 1999, 10, 365.

8. Miller, J.S.; Calabrese, J.C.; Epstein, A.J.; Bigelow, R.W.; Zhang, J.H.; Reiff, W.M.; J. Chem. Soc., Chem. Commun. 1986, 1026.

9. Pei, Y.; Verdaguer, M.; Kahn, O.; Sletten, J.; Renard, J.P.; J. Am. Chem. Soc. 1986, 108, 7428.

10. Stumpf, H.O.; Pei, Y.; Kahn, O.; Sletten, J.; Renard, J.P.; J. Am. Chem. Soc. 1993, 115, 6738.

11. Stumpf, H.O.; Pei, Y.; Michaut, C.; Kahn, O.; Renard, J.P.; Ouahab, L.; Chem. Mater., 1994, 6, 257.
12. Stumpf, H.O.; Ouahab, L.; Pei, Y.; Grandjean D.; Kahn, O.; Science 1993, 261, 271.

13. Meyers, C.; Meurdesoif, Y.; Leroyert, Y.; Kahn, O.; J. Phys. Condens. Matter 1998, 10, 2065.

14. Leandri, J.; Leroyert, Y.; Meshkov, S.V.; Kahn, O.; Mombelli, B.; Price, D.; J. Phys.: Condens. Matter 1996, 8, L271.

15. Kadam, R.M.; Sastry, M.D.; Mol. Cryst. Liq. Cryst. 1997, 306, 219.

16. Kadam, R.M.; Sastry, M.D.; Chem. Phys. Lett. 1997, 281, 292.

17. Sastry, M.D.; Bhide, M.K.; Chem. Phys. Lett. 1999, 4, 385.

18. Surville-Barland, C.; Ruiz, R.; Aukauloo, A; Journaux, Y.; Castro, I..; Cervera, B.; Julve, M.; Lloret, F.; Sapinã, F.; Inorg. Chim. Acta 1998, 278, 159.

19. Ruiz, R.; Surville-Barland, C.; Journaux, Y.; Colin, J.C.; Castro, I..; Cervera, B.; Julve, M.; Lloret, F.; Sapinã, F.; Chem. Mater. 1997, 9, 201.

20. Vaz, M.G.F.; Pinheiro, L.M.M.; Stumpf, H.O.; Alcântara, A.F.C.; Golhen, S.; Ouahab, L.; Cador, O.; Mathonière, C.; Kahn, O.; Chem. Eur. J. 1999, 5, 1486.

21. Kahn, O.; Ouahab, L.; Mathonière, C.; Stumpf, H.O. In Molecular Catenanes, Rotaxanes and Knots: a Journey Through the World of Molecular Topology. Sauvage, J.P.; Dietrich-Buchecker, C. eds.; Wiley-VCH: Weinheim, 1999, p 37.

22. Ulman, E.F.; Osiecki, J.H.; Boocock, D.G.B.; Darcy, R.; J. Am. Chem. Soc. 1972, 94, 7049

23. Stumpf, H.O.; Pei, Y.; Ouahab, L.; Le Berre, F.; Codjovi, E.; Kahn, O.; Inorg. Chem. 1993, 32, 5687.

24. Caneschi, A.; Gatteschi, D.; Rey, P.; Sessoli, R.; Inorg. Chem. 1988, 27, 1756; Caneschi, A.; Gatteschi, D.; Sessoli, R.; Rey, P.; Acc. Chem. Res. 1989, 22 , 392.

25. Stumpf, H. O., Ph.D. Thesis, Université de Paris-Sud, Orsay, France, 1993.

26. Kahn, O. In Molecular Magnetism, Verlag-Chemie: New York, 1993.

27. Vaz, M.G.F.; Stumpf, H.O.; Speziali, N.L.; Mathonière, C.; Cador, O.; Polyhedron, 2001, 20, 1761.

28. Herpin, A. In Théorie du magnétisme, Presses Universitares de France: Paris, 1968.

29. Stumpf, H. O.; Ouahab, L.; Pei, Y.; Bergerat, P.; Kahn, O.; J. Am. Chem. Soc. 1994, 116, 3866.

30. Cador, O.; Vaz, M.G.F.; Stumpf, H.O.; Mathonière, C.; Kahn, O.; Synth. Met., 2001, 122, 559.

Received: August 8, 2001 Published on the web: January 28, 2002

FAPESP helped in meeting the publication costs of this article. 